\title{
Effects of Variations in Salt-Spray Conditions on the Corrosion Mechanisms of an AE44 Magnesium Alloy
}

\author{
Holly J. Martin, M. F. Horstemeyer, and Paul T. Wang \\ Center for Advanced Vehicular Systems (CAVS), Mississippi State University (MSU), 200 Research Boulevard, Starkville, \\ MS 39759, USA \\ Correspondence should be addressed to Holly J. Martin, hmartin@cavs.msstate.edu
}

Received 31 October 2009; Accepted 12 January 2010

Academic Editor: S. Feliu Jr.

Copyright (๑) 2010 Holly J. Martin et al. This is an open access article distributed under the Creative Commons Attribution License, which permits unrestricted use, distribution, and reproduction in any medium, provided the original work is properly cited.

\begin{abstract}
The understanding of how corrosion affects magnesium alloys is of utmost importance as the automotive and aerospace industries have become interested in the use of these lightweight alloys. However, the standardized salt-spray test does not produce adequate corrosion results when compared with field data, due to the lack of multiple exposure environments. This research explored four test combinations through three sets of cycles to determine how the corrosion mechanisms of pitting, intergranular corrosion, and general corrosion were affected by the environment. Of the four test combinations, Humidity-Drying was the least corrosive, while the most corrosive test condition was Salt Spray-Humidity-Drying. The differences in corrosivity of the test conditions are due to the various reactions needed to cause corrosion, including the presence of chloride ions to cause pit nucleation, the presence of humidity to cause galvanic corrosion, and the drying phase which trapped chloride ions beneath the corrosion by-products.
\end{abstract}

\section{Introduction}

The search for lightweight solutions in the automobile and aerospace industry has created interest in the use of lightweight metallic alloys $[1,2]$. Interest in magnesium alloys has increased due to low density and high mechanical stiffness. However, when compared to aluminum or steel, magnesium has a high corrosion rate. Furthermore, magnesium alloys corrode easily in the presence of seawater, due to a high electrochemical potential as illustrated in the galvanic series [3]. Because of these corrosion issues, magnesium is currently used in locations that are not exposed to the environment, such as car seats and internal electronic boxes $[4,5]$. To deal with the seawater corrosion, magnesium alloys are currently being developed with the aim to reduce corrosion [4]. As such, the corrosion mechanisms of these magnesium alloys must still be determined.

Corrosion testing is usually performed using salt-water and one of two techniques: immersion or salt-spray in a cabinet. ASTM G-31 details the standards developed for corrosion testing based on immersion, while ASTM B117 details the standards developed for corrosion testing based on salt-spray $[6,7]$. Also, while the salt-spray standard has amendments for performing other experiments, such as acidified salt-spray, acidified seawater, and sulfur dioxide spray, there are no standards for cyclical salt-spray testing that do not involve removing the salt, only the acidified solution [8]. The need to examine cyclical saltspray testing has arisen, because a continuous salt-spray does not adequately replicate the corrosion of aluminum alloys exposed to a marine environment nor does it adequately replicate the data from corrosion field tests [9, 10]. Instead, engine cradles are exposed to many different environmental factors that make corrosive environments difficult to predict [11]. Because of the many different materials an engine block could encounter, such as deicing salt, mud, and condensation, it is important to test many different environments [11]. Companies have designed their own cyclical tests, which include a "pollution" phase and either a wet or dry phase [10]. However, none of these tests are identical, with varying concentrations of salt in the corrosive stages, varying degrees of temperature and humidity, and varying lengths of time [10]. While each test provides information about the corrosion of the metals, 
the corrosion mechanisms cannot be compared, only the final corrosive effects. Other research into the effects of salt on the corrosion of magnesium did not standardize the temperature or length of humid/drying conditions [12]. Instead, the cycle was standardized to two hours and the length of salt-spray and humid/drying conditions were changed [12]. Since the ultimate goal of this research is develop a model that explains pit nucleation, growth, and coalescence, the environmental effects must be standardized with respect to salt concentration, humidity, temperature, and cycle length. The particular goal of this research is to determine the most corrosive test cycle using a combination of standardized environmental effects that exposed magnesium would encounter, such as an aqueous saltspray, humidity, and drying. The weight loss, thickness loss, and stereological effects were determined for four environmental combinations on as-cast AE44 Mg (4.69\% Aluminum, 2.56\% Cesium (Rare Earth), 91.49\% Magnesium).

\section{Materials and Methods}

2.1. Testing. Thirty-six AE44 coupons $(2.54 \mathrm{~cm} \times 2.54 \mathrm{~cm}$ $\times$ varying thicknesses) were cut from an as-received engine cradle provided by Meridian Technologies using a vertical bandsaw (MSC Industrial Supply Company, Columbus, MS). The coupon surfaces were left untreated, to test the corrosion effects on an as-cast AE44 magnesium alloy. A QFog CCT (Q-Panel Lab Products, Cleveland, OH) was used to cycle through three stages, including drying air purge at $35^{\circ} \mathrm{C}, 100 \%$ humidity using distilled water at $35^{\circ} \mathrm{C}$, and a 3.5 wt. $\% \mathrm{NaCl}$ spray at $35^{\circ} \mathrm{C}$. Four test conditions combining at least two stages were run. The three test conditions that ran for two hours per cycle and six hours total consisted of Humidity-Drying (HD), Salt Spray-Humidity (SH), and Salt Spray-Drying (SD). The fourth test condition ran for three hours per cycle and nine hours total consisted of Salt Spray-Humidity-Drying (SHD). Nine coupons, hung at $20^{\circ}$ to the horizontal support shelf as recommended by ASTM B-117, were used per test condition with the removal of three coupons following each cycle, for a total of three cycles. Following the removal of the coupons after each cycle, the coupons were rinsed in distilled water to remove excess salt and corrosion by-products that were easily removed, and then dried. Between analyses, the coupons were stored in a desiccator to ensure that no further surface reactions occurred.

2.2. Analysis. Following each test cycle, the coupons were analyzed using optical microscopy and laser profilometry. The coupons were weighed prior to testing and following the test cycle on two different scales and an average was taken. Four thickness measurements were taken on each sample prior to and following the test. Because the coupons were cut from an engine cradle, the thicknesses of the coupons varied from side to side, meaning an average was taken per coupon based on the four measurements.

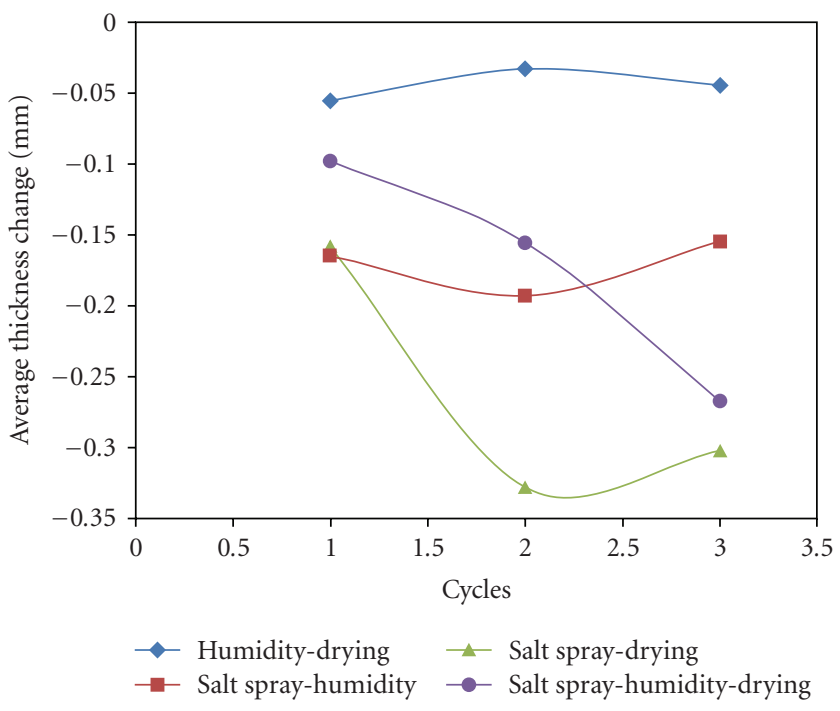

FIGURE 1: Average thickness loss of the AE44 coupons arranged by test condition based on cycle number. Note the almost parallel trend between the humidity-drying and the salt spray-humidity test conditions, as well as the almost parallel trend between the salt spray-drying and salt spray-humidity-drying test condition.

Optical microscopy with an inverted light was used to take multiple images of the resulting surface at $5 \times$ magnification and $10 \times$ magnification (Axiovert 200M Mat, Carl Zeiss Imaging Solutions, Thornwood, NY). The $5 \times$ magnification images were combined and then analyzed using the ImageAnalyzer (v. 2.1-2) provided by Mississippi State University to determine the number of pits, the pit surface area, the nearest neighbor radius, and the intergranular corrosion area fraction, to gain data for the development of a corrosion model not detailed in this paper, but previously outlined by Horstemeyer et al. [13]. The $10 \times$ magnification was used to document the changes over the three cycles. Laser profilometry was used to scan a $1 \mathrm{~mm} \times 1 \mathrm{~mm}$ area on each coupon following each test cycle (Talysurf CLI 2000, Taylor Hobson Precision Ltd, Leicester, England). The resulting $2 \mathrm{D}$ and $3 \mathrm{D}$ images were used to document the changes in the surface due to the different test conditions (Talymap Universal, v. 3.18, Taylor Hobson Precision Ltd, Leicester, England).

\section{Results}

Figure 1 shows the average thickness for each test condition per test cycle. The Humidity-Drying (HD) test condition, which acted as a control, showed the least amount of change in the thickness of the coupons. The Salt Spray-Humidity (SH) test condition also showed very little change in the thickness of the coupons over the cycle time, but showed more loss in thickness than the HD test condition. The Salt Spray-Humidity-Drying (SHD) test condition initially showed more thickness loss than the HD test condition but less than the SH test condition. Following Cycle 3, however, the SHD test condition caused more thickness loss than the 


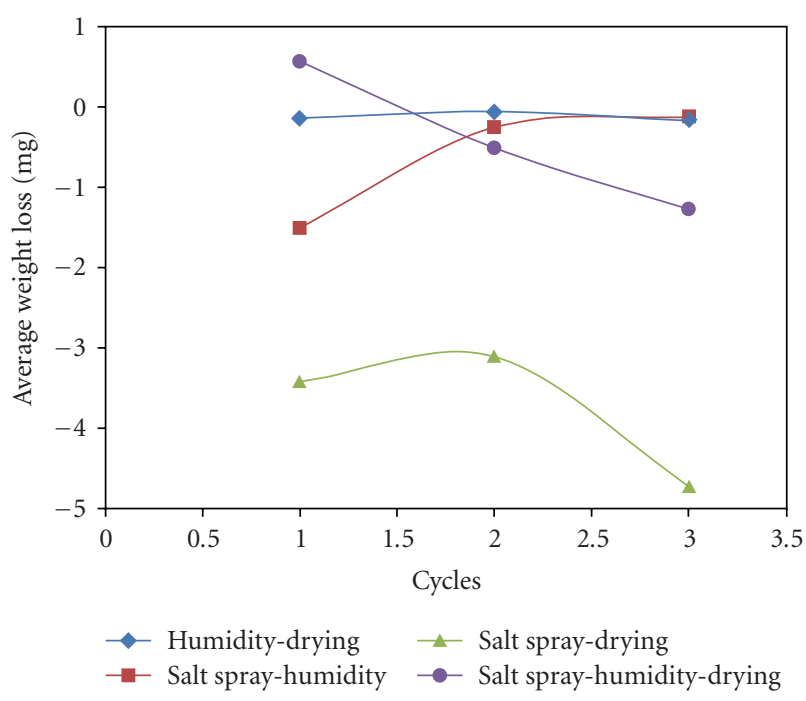

Figure 2: Average weight loss of the AE44 coupons arranged by test condition based on cycle number. Note the straight line of the humidity-drying test condition.

SH test condition. The test condition that caused the greatest thickness loss was the Salt Spray-Drying (SD) option, which was more corrosive through all three cycles than the other three test conditions.

Figure 2 shows the average weight loss for each test condition per test cycle. The HD test condition caused the least amount of weight loss during the three-cycle run. The $\mathrm{SH}$ test condition saw an initial decrease in weight following the first cycle, before no weight loss was seen following the third cycle. The SHD test condition initially saw a gain in weight following the first cycle, before an almost linear decrease in weight following the second and third cycles. The most drastic weight loss was observed by the SD test condition, which lost a total of $4.5 \mathrm{mg}$ over the three cycle run.

Figure 3 shows the pit number density, or the number of pits that formed, following each test cycle for each test condition. The HD test condition had the fewest number of pits formed over the entire set of cycles, although following Cycle 3, there were more pits on the HD surface as compared to the SD and the SHD test conditions. The SH test condition initially had the fewest pits formed following Cycles 1 and 2, even fewer than the HD test condition. Following Cycle 3 , however, the SH test condition had more pits on the surface than any of the other three test conditions. The SD test condition showed an increase in pit formation following Cycle 2, while Cycle 3 saw a decrease due to pit coalescence. The most significant pit formation was observed with the SHD test condition, as was the most significant decrease in pit number due to coalescence. Please note that, in order to fully see the points at the bottom of the graph, the second graph of Figure 3 was a zoomed-in portion close to the $x$ axis, which excluded the SHD cycle 1 point and the SH cycle 3 points. These changes did not affect the trends, but did affect the $y$-axis, which was necessary to see the slight changes that occurred close to zero.

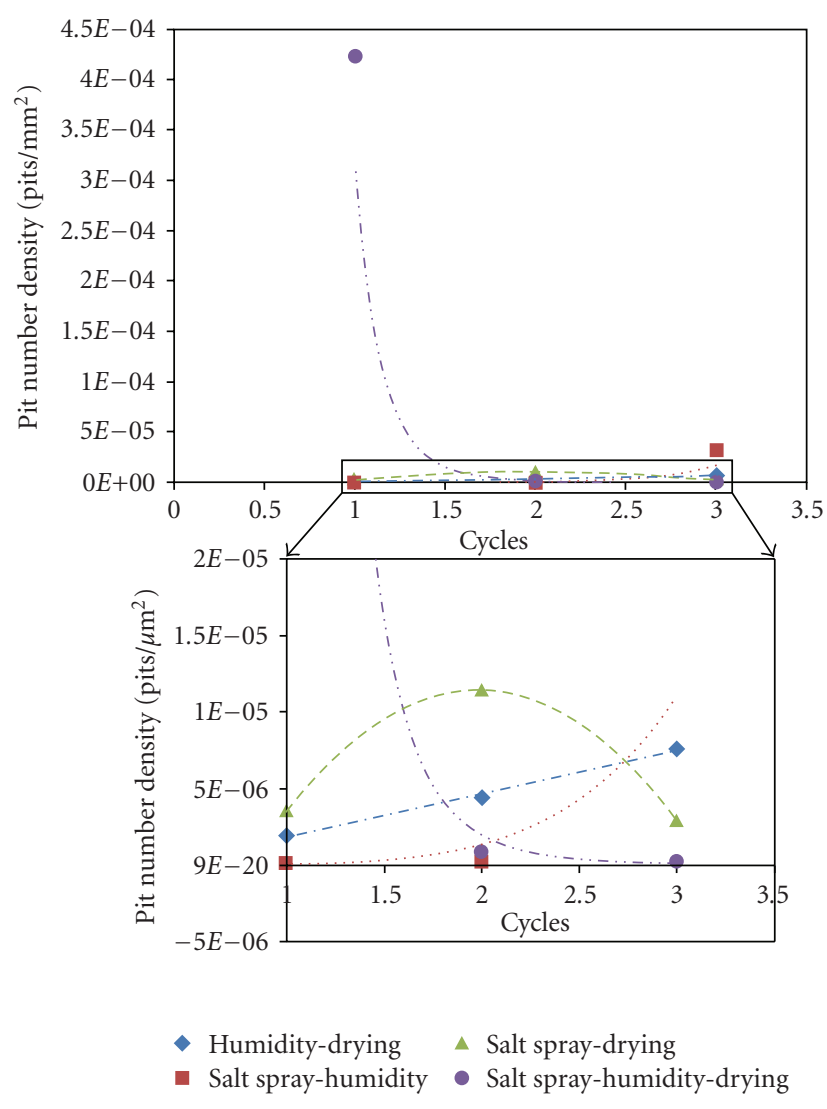

FIgURE 3: Average pit number density of the AE44 coupons arranged by test condition based on cycle number. Please note that the second graph was produced by focusing on the box surrounding the values close to the $x$-axis, in order to ensure that the values close to zero could be seen accurately.

Figure 4 shows the pit surface area, or the growth of the pits over time, following each test cycle for each test condition. The HD test condition showed a gradual increase in pit surface area over the three cycles tested, although the pits did fail to grow between Cycles 1 and 2. The SH test condition also showed a gradual increase in pit surface area over the three cycles tested, although the surface area of the pits was smaller than the largest values of the SD and SHD test conditions. The SD test condition showed an increase in pit surface area between Cycles 1 and 2, while a decrease was observed between Cycles 2 and 3. The SHD test condition showed the highest pit surface area following Cycle 1, with a drastic decrease following Cycle 2, with a similar value for Cycle 3 as compared to Cycle 2. The decrease in pit surface area of the SHD test condition was very similar to the final cycle of the SD test condition, both of which were less than the $\mathrm{SH}$ and $\mathrm{HD}$ test conditions.

Figure 5 shows the nearest neighbor distance, or the change in the distance between the pits as the pits grew, following each test cycle for each test condition. The HD test condition showed a gradual decrease in the nearest neighbor distance over the three cycles. The SH test condition also showed a decrease in the nearest neighbor distance over the 


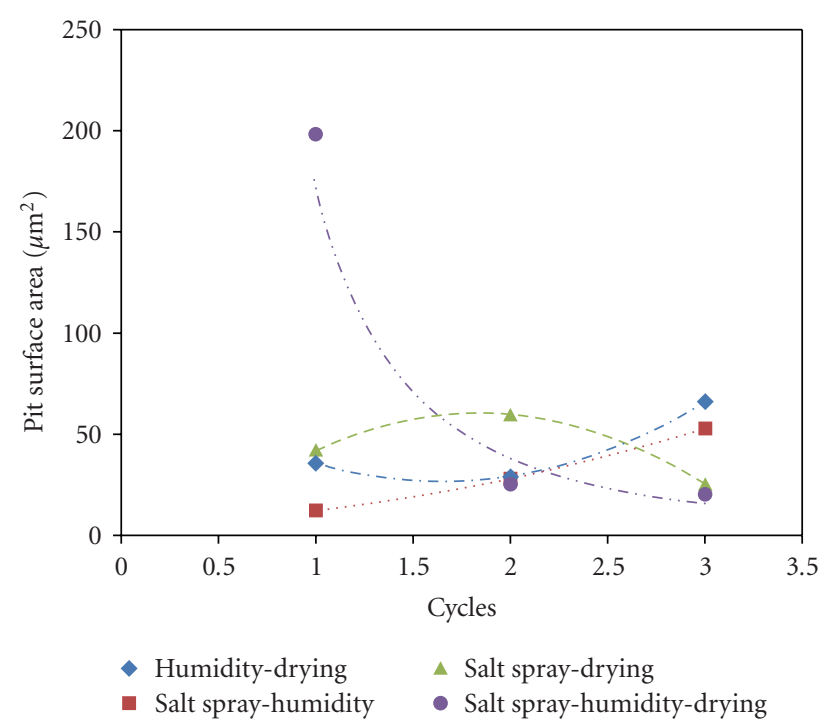

FIGURE 4: Average pit surface area of the AE44 coupons arranged by test condition based on cycle number.

three cycles tested, although the decrease was much larger than the other three test conditions. The SD test condition showed an initial decrease in the nearest neighbor distance between Cycles 1 and 2, while an increase was seen between Cycles 2 and 3. The SHD test condition showed the lowest nearest neighbor distance following Cycle 1, with an increase in the nearest neighbor distance following Cycle 2, followed by a decrease to Cycle 3. The value of the nearest neighbor distance of the SHD test condition following Cycle 3 was very similar to the final value of the SD test condition, both of which were larger than the SH and HD test conditions.

Figure 6 shows the intergranular corrosion area fraction, or the change in the surface as the pits coalesced, following each test cycle for each test condition. The HD test condition showed a gradual increase in the intergranular corrosion area fraction over the three cycles. The $\mathrm{SH}$ test condition also showed an increase in the intergranular corrosion area fraction over the three cycles tested. The SD test condition showed an increase in the intergranular corrosion area fraction over the three cycles tested, with an almost parallel trend to that of the HD test condition. The SHD test condition showed a decrease in the intergranular corrosion area fraction over the three cycles tested, with a starting value that was higher than the ending intergranular corrosion area fraction of the HD and SH test conditions and almost equal to the ending value of the SD test condition. The final value of the SHD test condition was almost equal to the beginning value of the SH test condition and lower than the other two test conditions.

Figure 7 shows the 3D laser profilometry scans of the coupons following the three cycles for the four test conditions. When looking at the 3D laser profilometry scans, one can observe where the corrosion initially took place based on the colors present. Where the reds, oranges, and yellows exist, the surface had not been heavily corroded, while the greens and blues indicate corrosion, due to the

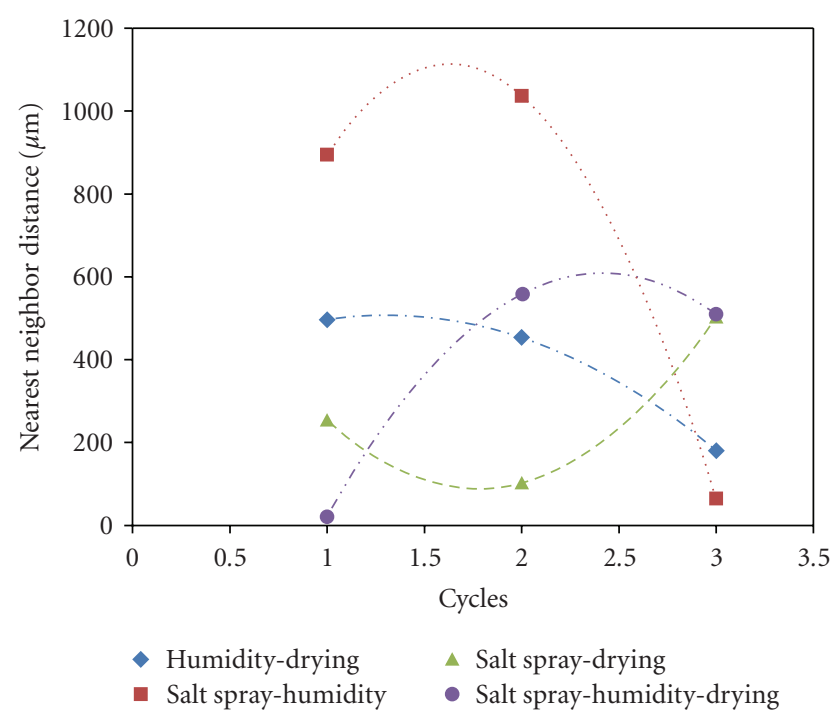

FIgURE 5: Average nearest neighbor distance of the AE44 coupons arranged by test condition based on cycle number.

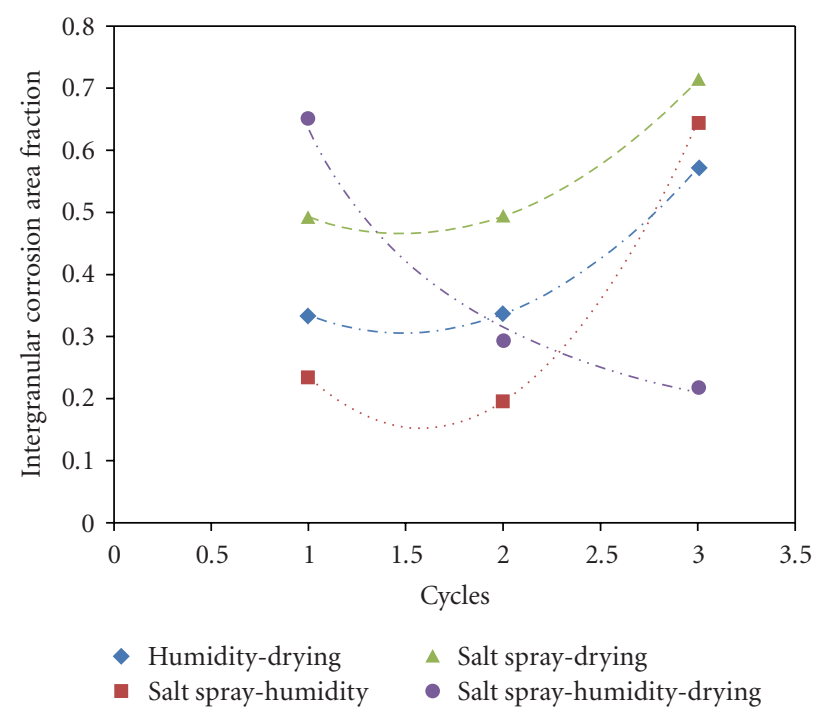

Figure 6: Average intergranular corrosion area fraction of the AE44 coupons arranged by test condition based on cycle number.

removal of material. Looking at the Cycle 1 column, one can see that the least corroded surface was the HD surface, while the most corroded surface was the SHD surface, based on the combination of reds and blues. As one moves to Cycle 2 column, an increase in blue and a decrease in red can be seen on all four rows, again showing that the most corroded surface was the SHD surface and the least corroded surface was the HD surface. Finally, as one reaches the Cycle 3 column, intergranular corrosion was almost completely gone on the SHD test condition, as demonstrated by the almost complete lack of yellow and red peaks. The other three surfaces were still experiencing intergranular corrosion, with the most heavily intergranular corroded surface being that of $\mathrm{SD}$, while the HD surface was still the least corroded surface. 

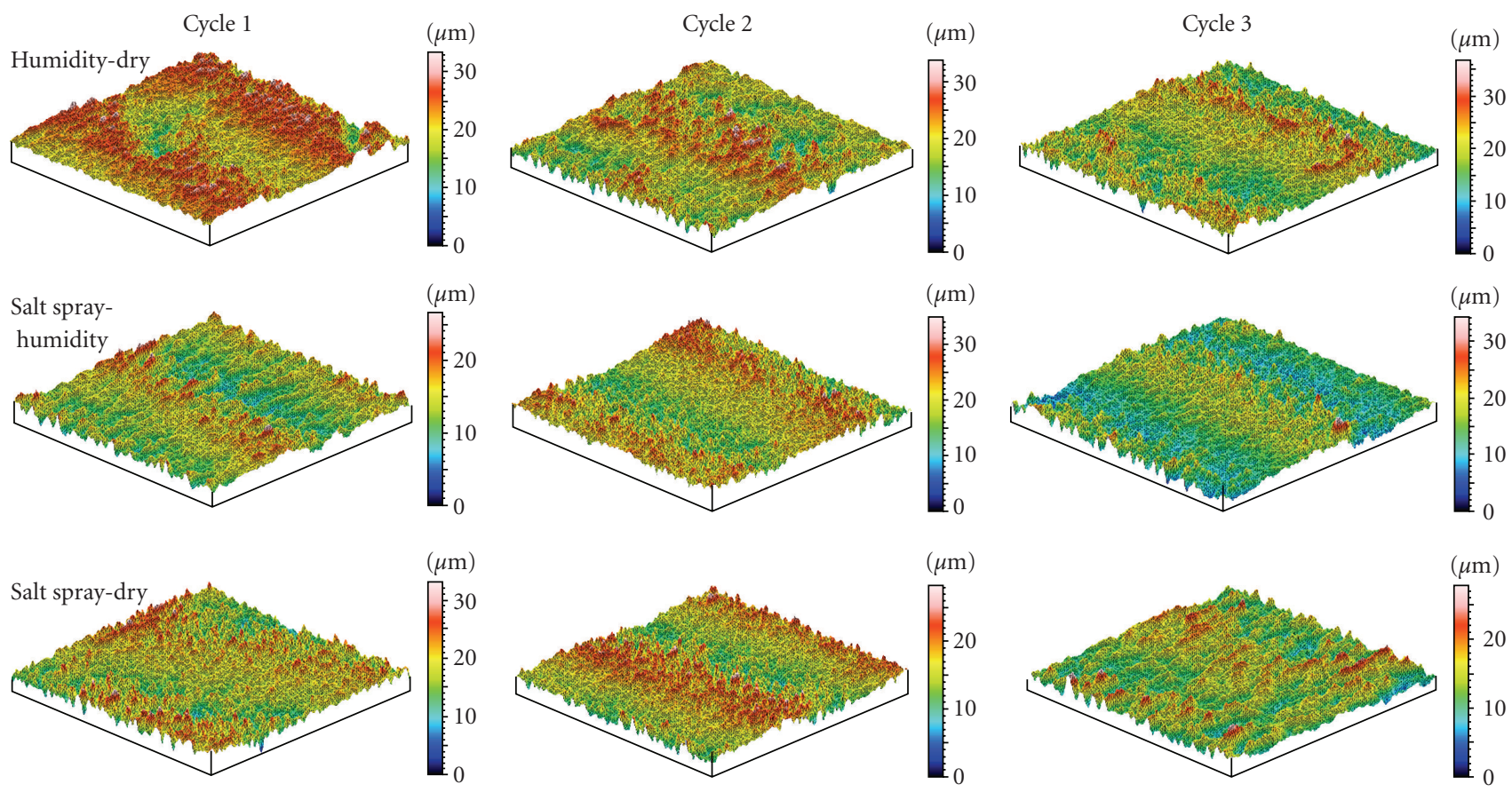

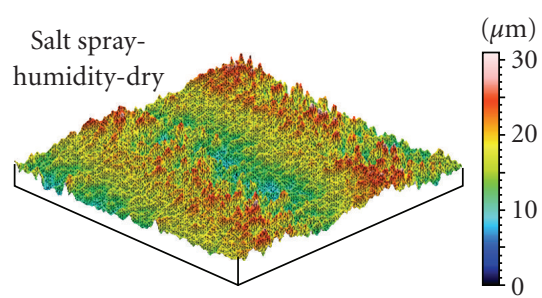

(a)

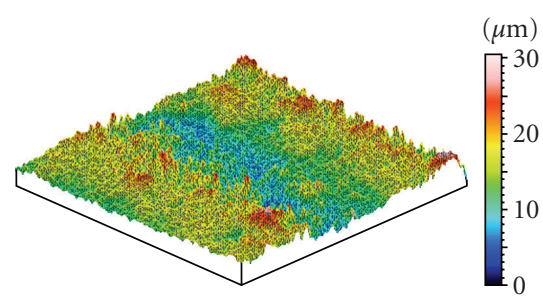

(b)

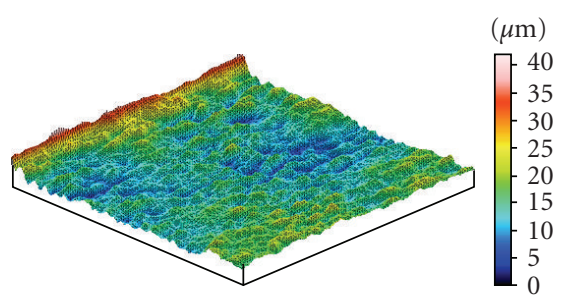

(c)

FIGURE 7: 3D Laser profilometry of the AE44 coupons arranged by test condition based on cycle number. The blue colors correspond to the lowest surface values, while the pink colors represent the highest surface values. Notice the increasing amount of intergranular corrosion following each cycle, as denoted by an increase in the connecting blue areas and a decrease in the red peaks.

Figure 8 shows the 2D laser profilometry scans of the coupons following the three cycles for the four test conditions. As with the 3D laser profilometry scans, one can observe where the corrosion initially took place based on the colors present in the $2 \mathrm{D}$ scans. Where the reds, oranges, and yellows exist, the surface had not been heavily corroded, while the greens and blues indicate corrosion, due to the removal of material. Looking at Cycle 1 column, one can see that the least corroded surface was the HD surface, while the most corroded surface was the SHD surface, based on the combination of reds and blues. The dark blue spots on the SH, SD, and SHD indicated the formation of pits following the first exposure. One can see that more pits were present on the SHD surface as compared to the other three surfaces. As one moves to the Cycle 2 column, an increase in blue, especially on the SHD surface, indicated the formation of more pits, as well as pit coalescence. Finally, Cycle 3 showed an increase in intergranular corrosion, as the pits coalesced and increases in blue and green appear. The large amount of blues and green on the SHD surface indicated that the surface had been heavily corroded and the dominant corrosion mechanism was general corrosion, instead of pitting or intergranular corrosion.

Figure 9 shows the micrographs taken at 10x magnification. Please note that the scale bar indicates a $1000 \mu \mathrm{m}$ surface, which is the same size as the laser profilometry scans. As one can see in the Cycle 1 column, the most heavily pitted surface as indicated by the presence of "black spots," were the SD and the SHD surfaces. The least corroded surfaces were the SH and the HD surfaces. Following Cycle 2, the presence of the "black spots" decreased on the SHD surface, while the "black spots" increased on the SD surface. Finally, Cycle 3 showed an increase in the "black spots" on the HD surface. An increase in intergranular corrosion is also seen in Cycle 3, as indicated by the formation of "shapes" due to pit coalescence.

\section{Discussion}

Figures 1 and 2, which show the average losses in coupon thickness and weight, respectively, seem to indicate that the most corrosive salt-spray method is the Salt SprayDrying (SD) cycle, which resulted in the most thickness 

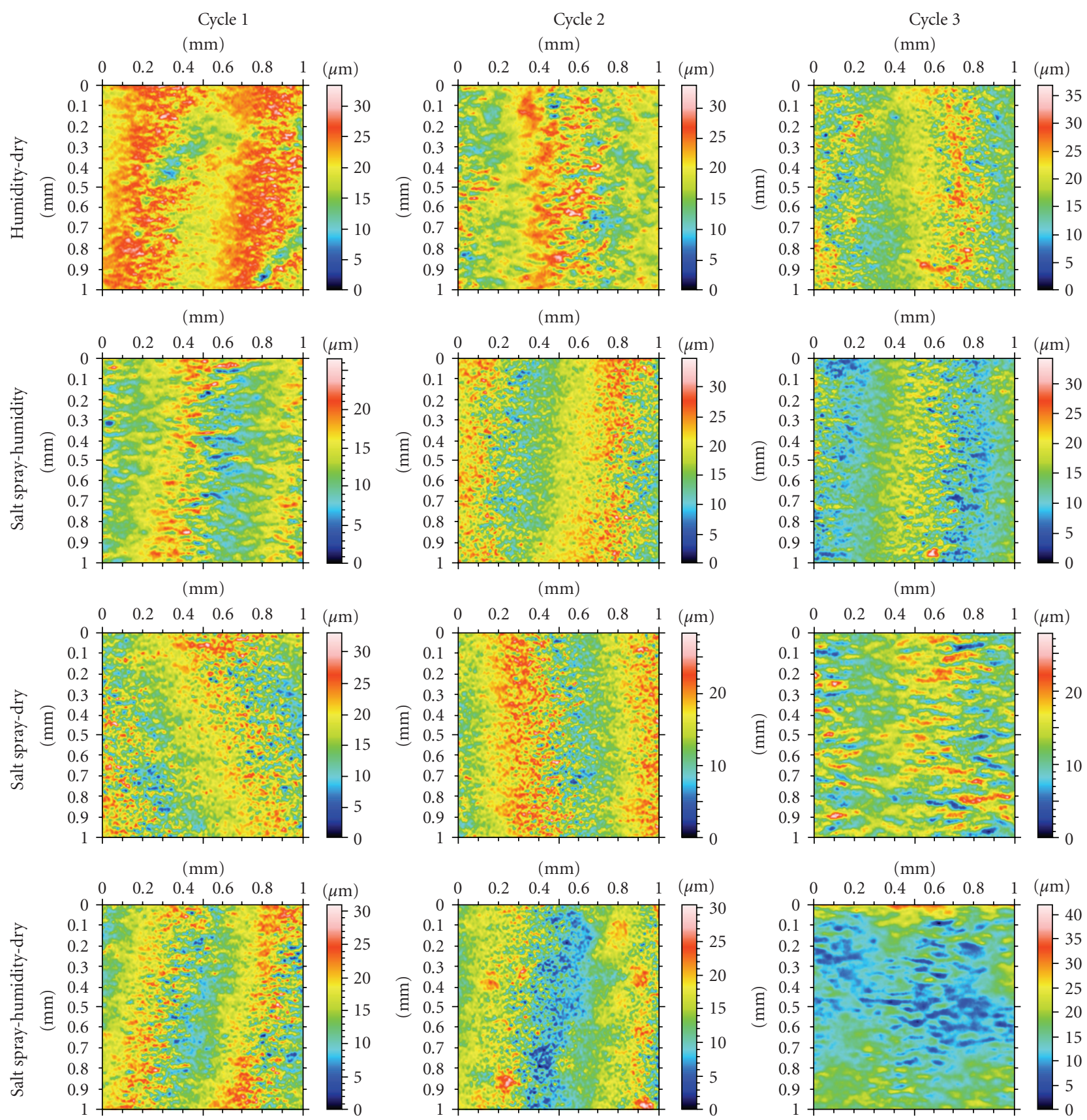

(a)

(b)

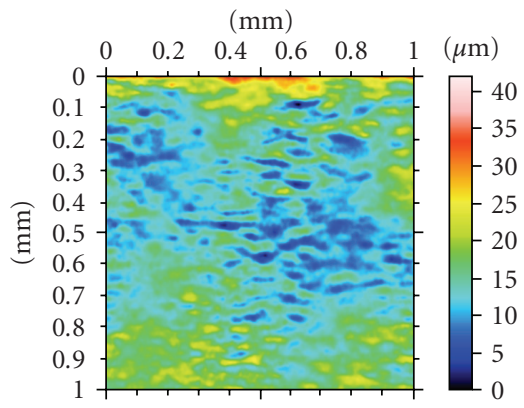

(c)

Figure 8: 2D Laser Profilometry of the AE44 coupons arranged by test condition based on cycle number. The blue colors correspond to the lowest surface values, while the pink colors represent the highest surface values. Notice the increasing amount of intergranular corrosion following each cycle, as denoted by an increase in the connecting blue areas and a decrease in the red peaks.

loss and weight loss. However, thickness and weight loss only document the general corrosion of the magnesium alloy coupons. While general corrosion is one corrosion mechanism, two other corrosion mechanisms, pitting and intergranular corrosion, also take place on the AE44 Mg coupons. Using the thickness loss and weight loss as the only determination of corrosion excludes the effects of pitting, which only causes a very small weight loss [14].
Because pitting negatively affects the entire structure, but only locally inducing stress concentrations and/or damage paths, different techniques must be used to determine the true effects of the four test conditions.

Figures 3-6 graphically show the effects of pitting on the magnesium coupons, while Figure 7-9 pictorially show these pitting effects. When one looks at these figures, one can see the initial formation of pits on the three surfaces 

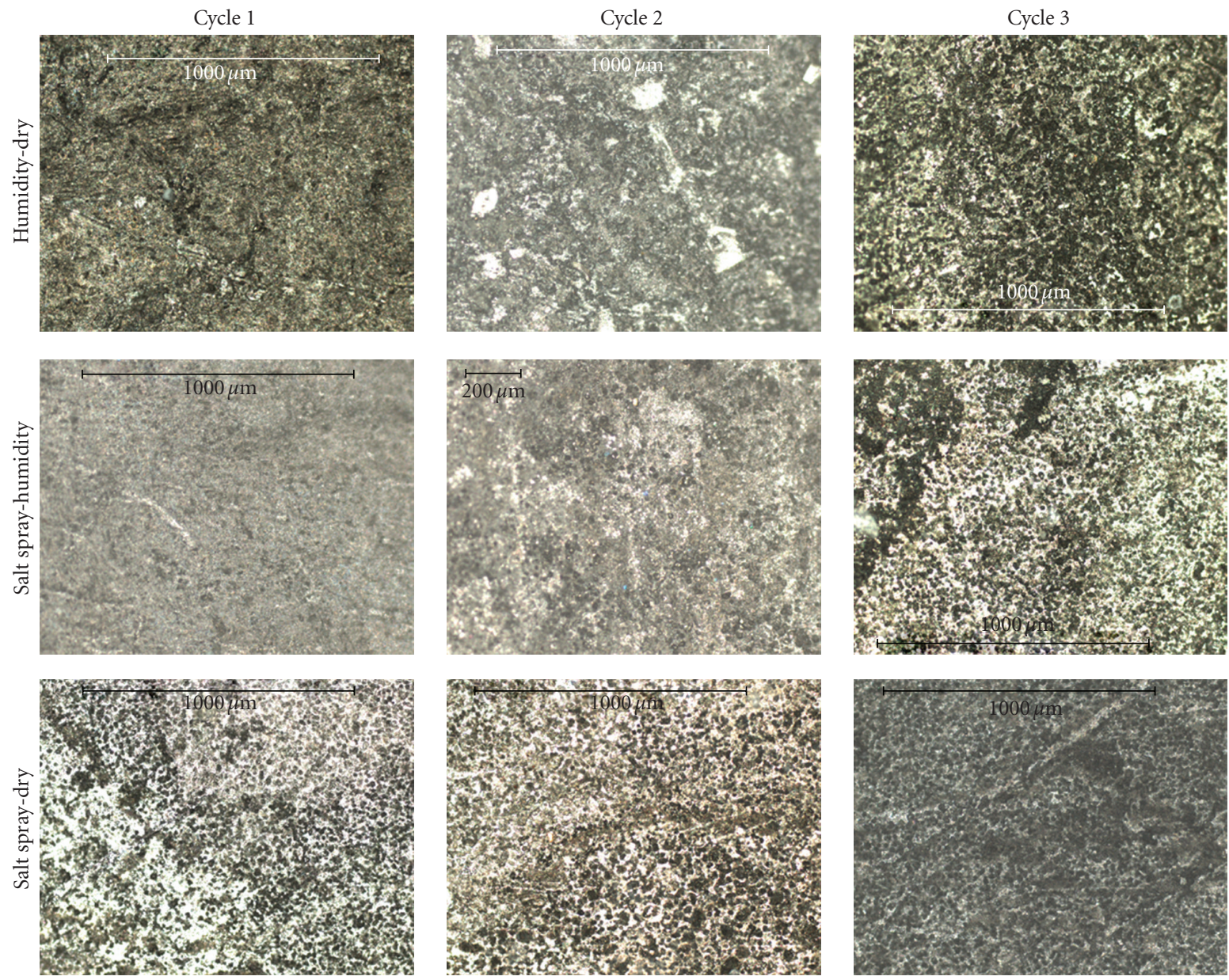

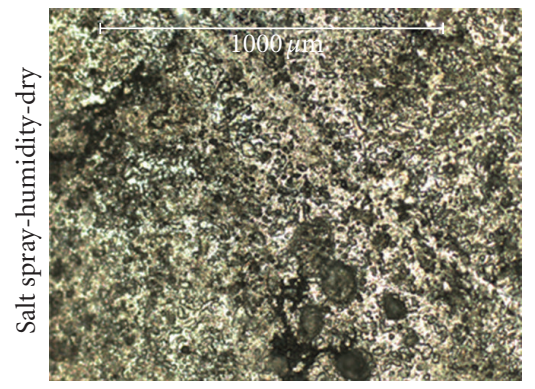

(a)

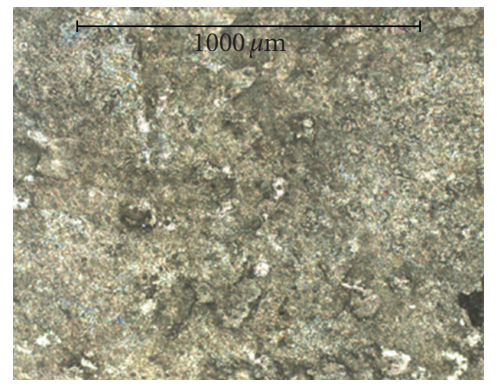

(b)

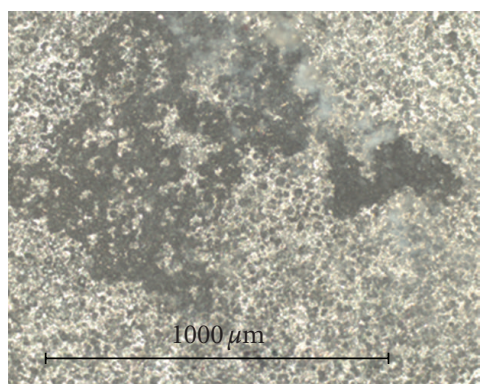

(c)

FIGURE 9: Micrographs of the AE44 coupons arranged by test condition based on cycle number. The scale for all of the pictures is $1000 \mu \mathrm{m}$ long. Notice the presence of dark spots, indicating the formation of pits, specifically in the first and second columns, as well as the connection of the pits, specifically in the third column.

exposed to the salt spray, while few pits formed on the Humidity-Drying (HD) surfaces. Pitting is initiated by the chloride ions released by dissolving $\mathrm{NaCl}$ in water. These chloride ions are then part of an autocatalytic process, which helps continue the growth of the pits [14]. Humidity provided water, which is necessary for the cathodic reaction that initiates the dissolution of the metal [14]. In addition, humidity provides extra hydrogen necessary to continue the pitting reaction. Finally, humidity would also remove the build-up of corrosion products produced by pit formation.
The presence of humidity explains why some corrosion was present on the HD coupons and why corrosion continued on the Salt Spray-Humidity (SH) and the Salt Spray-HumidityDrying (SHD) coupons. When the samples were dried, the cycle of corrosion on the surface stopped, as hydrogen was no longer present. However, the pits, with a build-up of corrosion products surrounding the pits, likely trapped the water, allowing pit growth and coalescence. The trapped water explains why there were more pits following Cycle 2 on the SD coupons. 
The control reaction series was the HD test condition. Figure 3 shows that some pits were present on the surface following Cycle 1. However, these pits were likely the casting pores, as there was no salt to provide the chloride ions necessary to initiate pit formation. The pit surface area did not change between the three cycles, further confirming that these were casting pores and not true pits (Figure 4). If the pits formed on the HD coupons were true pits, these should grow over time. If, however, these "pits" were casting pores, then there would be no growth, because there would be no reaction to continue to the pit nucleation and growth. There was some decrease in the nearest neighbor distance (Figure 5), but this could also be contributed to the increase in intergranular corrosion, as shown in Figure 6. The humidity provided water for galvanic corrosion between the eutectic phase and the magnesium grains $[15,16]$. One can see the change in intergranular corrosion when looking at Figures 7-9. Figures 7 and 8 show an increase in the green and blue peaks, as intergranular corrosion removed the eutectic phase, while a decrease in the red and orange colors are decreased to general corrosion removing the peaks. Figure 9 further confirms this trend, as the intergranular corrosion, or dark grey areas, are increased, while the top surface, shown white on Cycle 2, is also decreased. The full corrosion potential of HD test condition was not determined with these experiments, as only three cycles, or six hours, were performed.

Looking at Figures 3-5, one can see that the $\mathrm{SH}$ test condition had the most pits formed following Cycle 3, even though this test condition had the fewest pits formed following Cycle 1 (Figure 3). Because there were so few pits on the surface following Cycle 1, there was little surface area covered by the pits, although the pit surface area did increase following each of the remaining two cycles (Figure 4). The nearest neighbor distance also decreased following each cycle, as the pit surface area increased, meaning the pits were growing closer together (Figure 5). In addition to the nearest neighbor distance, the intergranular corrosion area fraction also increased (Figure 6). The low number of pits on the surface could be contributed to difficulty in pit initiation. However, once the pits did begin to grow, the salt-spray continued to provide the necessary chloride ions for the reaction. The presence of humidity allowed the pits to grow and encouraged a galvanic reaction, which would increase the intergranular corrosion area fraction [15, 16]. The combination of salt-spray and humidity promoted pitting and intergranular corrosion, which can be seen when examining Figures 7 and 8. One can see some pitting on the 2D surface following Cycle 1, while more pitting occurred following Cycle 3 (Figure 8). The presence of intergranular corrosion can be more clearly seen on the 3D surface, as more red peaks are present on following Cycle 3 as compared to Cycle 1, indicating that the area between the peaks was removed. Figure 9, the optical micrographs, shows the change from low pitting in Cycle 1 to high pitting in Cycle 3, as shown by the increase in dark spots. The optical micrographs also show the change from low intergranular corrosion in Cycle 1 to high intergranular corrosion in Cycle 3 , as shown by an increase in the presence of connected dark "lines" in the upper left corner. The dominant corrosion mechanism was a combination of pitting and intergranular corrosion. Because these experiments were performed for three cycles, or six hours, no switch to general corrosion was observed.

The SD test condition showed an increase in the number of pits following Cycle 2, before the number of pits dropped following Cycle 3 (Figure 3). The same trend can be observed in the surface area of the pits (Figure 4). The number of pits and the surface area of the pits likely increased because the chloride ions were trapped beneath the corrosion byproducts following Cycle 1, which dried the corrosion byproducts in place. Following the second cycle, which exposed the coupons to a $3.5 \% \mathrm{NaCl}$ aqueous solution, the corrosion by-products were removed, which allowed the pits to grow (increase in surface area) and continue nucleation (increase in pit number density). The nearest neighbor distance decreased following Cycle 2 because more pits were present, as were larger pits (Figure 5). Following Cycle 3, however, the number of pits and the pit surface area decreased, while the intergranular corrosion area fraction increased (Figure 6). These changes occurred because the water present in the $3.5 \% \mathrm{NaCl}$ aqueous solution allowed galvanic corrosion to occur, creating intergranular corrosion between the eutectic phase and the $\mathrm{Mg}$ grains $[15,16]$. If one looks at Figures 8 and 9 , the changes in pit number density and intergranular corrosion can be seen. There are few blue spots in Figure 9 following Cycle 1, while the blue spots have become more numerous following Cycle 3, as intergranular corrosion removed material between the pits. The red and orange peaks, more numerous following Cycle 2, have also been reduced-an indication that general corrosion has started occurring on these coupons. Finally, the optical micrograph images show a gradual switch from pitting and intergranular corrosion to general corrosion. Following Cycle 1, pitting is dominate, shown by the dark spots, while following Cycle 2, intergranular corrosion and pitting are both occurring. Intergranular corrosion is still present following Cycle 3, as shown by the dark grey spots in the center of the image, while general corrosion has removed some of the brighter spots present following Cycle 2. However, because these experiments were performed for three cycles, or six hours, the full switch to general corrosion was not observed.

Finally, one can see that the SHD test condition had the most pits formed following Cycle 1 (Figure 3). The area of the pits was the highest following Cycle 1 (Figure 4), while the nearest neighbor distance increased following each cycle (Figure 5). The high number of pits on the surface meant that the surface area covered by the pits would also be high, while the nearest neighbor distance would be small, since the pits were covering the entire surface. The high number of initial pits is likely due to the presence of salt, which initiated pit nucleation. The presence of humidity both allowed the pits to grow as the autocatalytic reaction continued, as well as corrosion caused by a galvanic reaction (Figure 6) $[15,16]$. However, the presence of salt and humidity does not explain the decrease in pit number density, pit surface area, or intergranular corrosion area fraction, following Cycle 1. One must instead look at images produced using 
laser profilometry (Figures 7 and 8 ) and optical microscopy (Figure 9). As one can observe, the surface peaks change when comparing Cycle 1 to Cycle 3. The amount of red and orange colors, indicating height, decreases between each cycle, while the amount of blues and greens, indicating depth, increases. Following Cycle 1, the dominant corrosion mechanism on the SHD cycle switched from pitting to general corrosion. This switch is further confirmed when examining Figure 9. The dark areas indicating pits have decreased following Cycle 3, especially when compared to the optical micrograph following Cycle 1. Since these experiments only went through three cycles, it remains to be seen what occurs following nine hours of reaction time.

\section{Conclusions}

This research covered the corrosive effects of four cyclical salt-spray environments on an as-cast AE44 Mg alloy. Some clear conclusions relating to the surface corrosion, specifically with respect to pitting corrosion and intergranular corrosion, can be drawn from this research.

(i) The Salt Spray-Drying cycle was the most corrosive cycle based on weight and thickness loss, but the pitting corrosion mechanisms under examination were much lower on the Salt Spray-Drying cycle as compared to the Salt Spray-Humidity-Drying.

(ii) The Salt Spray-Humidity-Drying cycle was the most corrosive cycle, with the highest number of pits and the largest pit area following the initial exposure to the environment.

(iii) General corrosion quickly "caught" pitting corrosion on the Salt Spray-Humidity-Drying cycle, resulting in removal of the AE44 Mg surface.

(iv) For all cycles, the pit number density and the pit area followed similar trends, while the nearest neighbor distance followed similar trends, but were inversely related to the pit number density and pit area.

\section{Acknowledgments}

The financial support from the Center for Advanced Vehicular Systems (CAVS) at Mississippi State University is gratefully acknowledged. The support from Meridian Technologies, which provided the AE44 Mg engine cradle, is deeply appreciated. This work was also supported by the Department of Energy and the National Energy Technology Laboratory under Award no. DE-FC26-02OR22910. This paper was prepared as an account of work sponsored by an agency of the United States Government. Neither the United States Government nor any agency thereof, nor any of their employees, makes any warranty, expressed or implied, or assumes any legal liability or responsibility for the accuracy, completeness, or usefulness of any information, apparatus, product, or process disclosed, or represents that its use would not infringe privately owned rights. Reference herein to any specific commercial product, process, or service by trade name, trademark, manufacturer, or otherwise does not necessarily constitute or imply its endorsement, recommendation, or favoring by the United States Government or any agency thereof. The views and opinions of authors expressed herein do not necessarily state or reflect those of the United States Government or any agency thereof. Such support does not constitute an endorsement by the Department of Energy of the work or the views expressed herein.

\section{References}

[1] J. D. Majumdar, R. Galun, B. L. Mordike, and I. Manna, "Effect of laser surface melting on corrosion and wear resistance of a commercial magnesium alloy," Materials Science and Engineering A, vol. 361, no. 1-2, pp. 119-129, 2003.

[2] C. Blawert, E. D. Morales, W. Dietzel, and K. U. Kainer, "Comparison of corrosion properties of squeeze cast and thixocast MgZnRE alloys," Materials Science Forum, vol. 488489, pp. 697-700, 2005.

[3] G. L. Makar and J. Kruger, "Corrosion of magnesium," International Materials Reviews, vol. 38, pp. 138-153, 1993.

[4] G. Song and A. Atrens, "Understanding magnesium corrosion-a framework for improved alloy performance," Advanced Engineering Materials, vol. 5, no. 12, pp. 837-858, 2003.

[5] B. A. Shaw, "Corrosion resistance of magnesium alloys," in ASM Handbook, L. J. Korb, Ed., p. 692, ASM International Handbook Committee, Metals Park, Ohio, USA, 9th edition, 2003.

[6] ASTM G31-72, "standard practice for laboratory immersion corrosion testing of metals," vol. 03.02, 2004.

[7] ASTM B117-07, "Standard practice for operating salt spray (sog) spparatus," vol. 03.02, 2007.

[8] ASTM G85-09, "Standard practice for modified salt spray (fog) testing," vol. 03.02, 2009.

[9] K. R. Baldwin and C. J. E. Smith, "Accelerated corrosion tests for aerospace materials: current limitations and future trends," Aircraft Engineering and Aerospace Technology, vol. 71, no. 3, pp. 239-244, 1999.

[10] N. LeBozec, N. Blandin, and D. Thierry, "Accelerated corrosion tests in the automotive industry: a comparison of the performance towards cosmetic corrosion," Materials and Corrosion, vol. 59, no. 11, pp. 889-894, 2008.

[11] G. Song, D. St John, C. Bettles, and G. Dunlop, “The corrosion performance of magnesium alloy AM-SC1 in automotive engine block applications," Journal of Operations Management, vol. 57, no. 5, pp. 54-56, 2005.

[12] M. C. Zhao, P. Schmutz, S. Brunner, M. Liu, G.-l. Song, and A. Atrens, "An exploratory study of the corrosion of $\mathrm{mg}$ alloys during interrupted salt spray testing," Corrosion Science, vol. 51, no. 6, pp. 1277-1292, 2009.

[13] M. F. Horstemeyer, J. Lathrop, A. M. Gokhale, and M. Dighe, "Modeling stress state dependent damage evolution in a cast Al-Si-Mg aluminum alloy," Theoretical and Applied Fracture Mechanics, vol. 33, no. 1, pp. 31-47, 2000.

[14] M. G. Fontana, "Corrosion principles," in Corrosion Engineering, M. G. Fontana, Ed., pp. 12-38, McGraw-Hill, Boston, Mass, USA, 1986. 
[15] G. Pettersen, H. Westengen, R. Hoier, and O. Lohne, "Microstructure of a pressure die cast magnesium-4wt.\% aluminium alloy modified with rare earth additions," Materials Science and Engineering A, vol. 207, no. 1, pp. 115-120, 1996.

[16] P. Bakke and H. Westengen, "The role of rare elements in structure and property control of magnesium die casting alloy," in Magnesium Technology, N. R. Neelameggham, H. I. Kaplan, and B. R. Powell, Eds., pp. 291-296, TMS, 2005. 

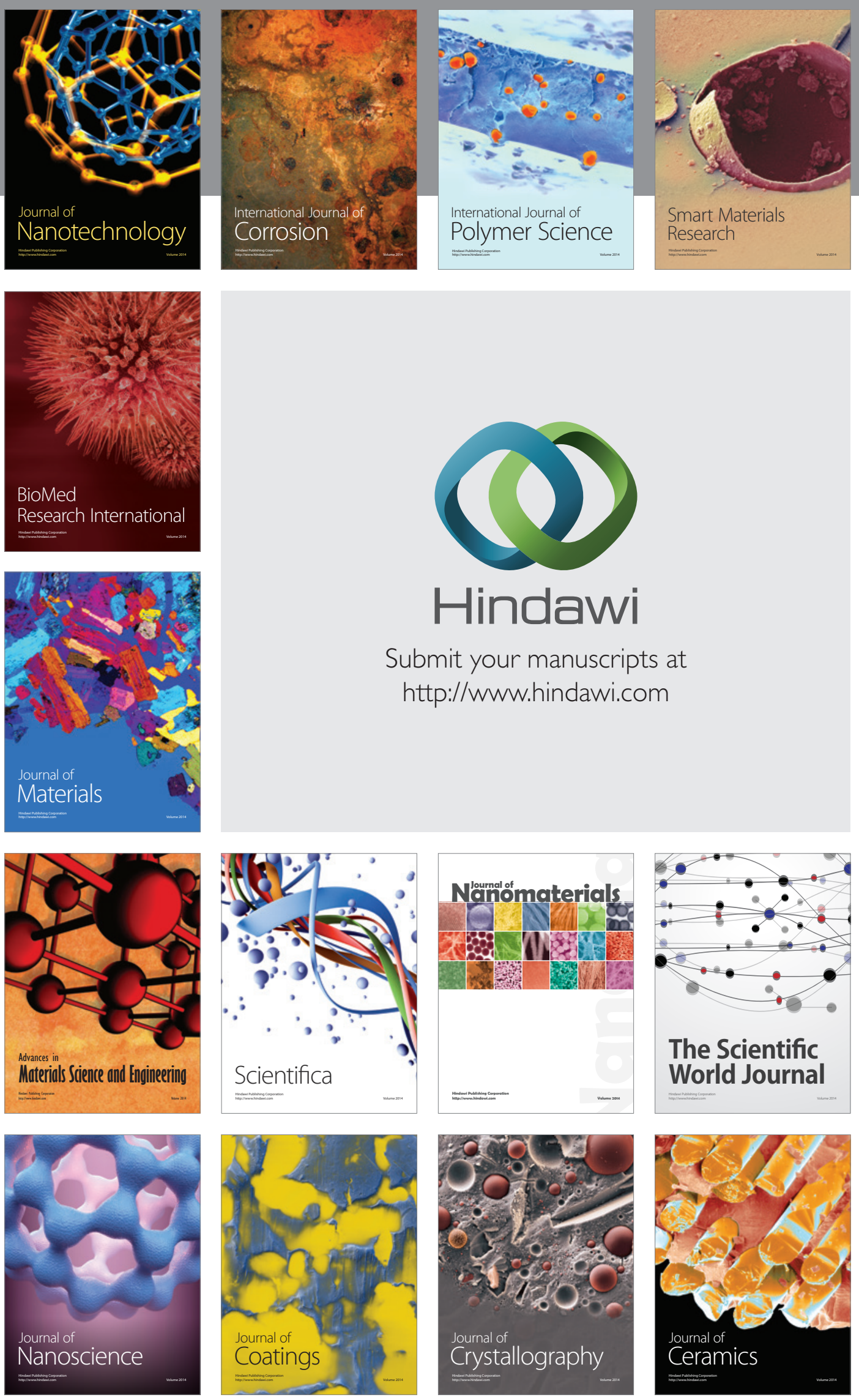

The Scientific World Journal

Submit your manuscripts at

http://www.hindawi.com

\section{World Journal}

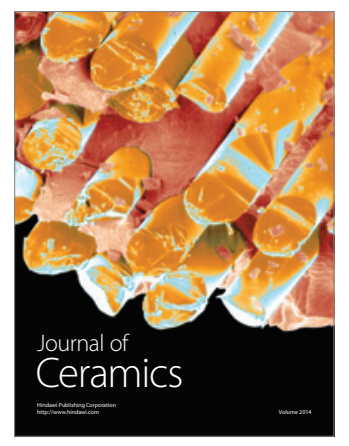

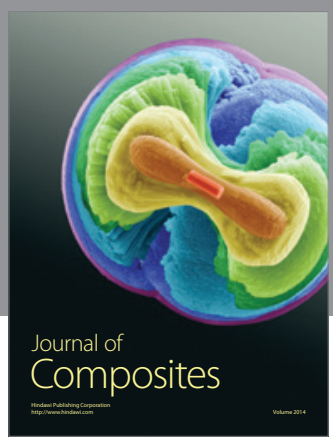
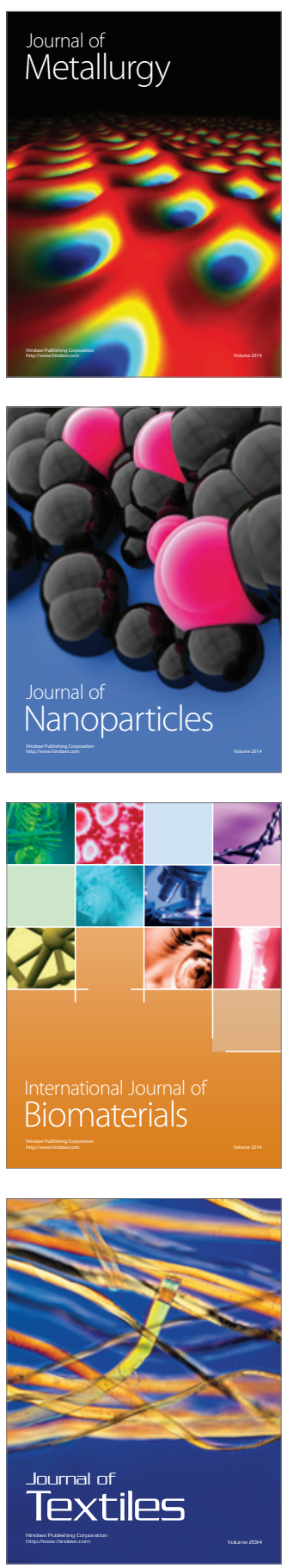